\title{
Ovarian, Fallopian Tube, and Primary Peritoneal Carcinoma Pathologic Distant Metastasis TNM Finding v8
}

National Cancer Institute

\section{Source}

National Cancer Institute. Ovarian, Fallopian Tube, and Primary Peritoneal Carcinoma

Pathologic Distant Metastasis TNM Finding v8. NCI Thesaurus. Code C139935.

A pathologic finding about one or more characteristics of ovarian, fallopian tube, or primary peritoneal carcinoma, following the rules of the TNM AJCC v8 classification system as they pertain to distant metastases. 